\title{
Comparison of diagnostic accuracy of bactec culture, gene-xpert and histopathology in the diagnosis of genital tuberculosis in women with infertility
}

\author{
Rachna Chaudhary, Vandana Dhama, Manisha Singh*, Shakun Singh
}

Department of Obstetrics and Gynecology, LLRM Medical College, Meerut, Uttar Pradesh, India

Received: 28 January 2020

Accepted: 28 February 2020

*Correspondence:

Dr. Manisha Singh,

E-mail: manishasinghgsvm@gmail.com

Copyright: (C) the author(s), publisher and licensee Medip Academy. This is an open-access article distributed under the terms of the Creative Commons Attribution Non-Commercial License, which permits unrestricted non-commercial use, distribution, and reproduction in any medium, provided the original work is properly cited.

\section{ABSTRACT}

Background: Female genital tuberculosis (FGTB) is often a silent disease sparing no age group but majority of patients are in the reproductive age. In infertility patient's incidence of FGTB varies from 3-16\% in India but the actual incidence of genital tuberculosis may be under reported due to asymptomatic presentation and paucity of investigations.

Methods: Prospective case control study was conducted from June 2018 to May 2019 in LLRM Medical College Meerut. A total 100 Endometrial samples were collected during diagnostic laparoscopy from all suspected case of genital TB, presented with either primary or secondary infertility and samples sent for histopathology, Gene-xpert and Bactec culture.

Results: Out of 100 samples Bactec culture was positive in 2 samples, Gene-xpert positive in 3 samples. On histopathology out of 100 cases, non-specific endometritis was found in 1 case, tubercular-endometritis in 1 case, proliferative enometrium (anovulatory) in 40 cases and secretory endometrium found in 58 cases.

Conclusions: Female genital TB poses a diagnostic dilemma because of its varied presentation and lack of sensitive and specific method of diagnosis. Culture though remains the gold standard of diagnosis of female genital TB, genexpert, histopathology, Bactec culture or laparoscopy can be used for starting treatment. Endometrial biopsy on histopathology shows not only Tubercular endometritis but also gives hormone response on endometrium, local factors of endometrium concerning non-specific and specific infections and anovulatory cycles.

Keywords: Bactec culture, Gene-xpert, Histopathology, Infertility, Laparoscopy

\section{INTRODUCTION}

Infertility is defined as inability to conceive even after one year of unprotected sexual intercourse. There are various causes that result in infertility out of which genital tuberculosis is one of the important causes of infertility, especially in developing countries including India. Genital tuberculosis is a chronic disease and is almost always secondary and often has low grade symptomatology with very few specific complaints. It is estimated that $11 \%$ of patients lack symptoms. ${ }^{1}$ The fallopian tubes are the initial site of involvement being affected in $100 \%$ cases of genital tuberculosis, followed by endometrium $(50-60 \%)$, ovaries $(20-30 \%)$, cervix (5$15 \%)$, vulva and vagina (1\%). Most cases of confirmed genital tuberculosis will have a perfectly normal clinical examination, while a quarter of cases will present with an adenexal mass. $^{2}$

Diagnosis of GT in early stage is very difficult. Early diagnosis may be associated with a favourable result before extensive genital damage occurs. Common presenting symptoms are nonspecific; hence diagnosis is difficult and elusive as affected patients have normal 
serological tests like hemogram including TLC and DLC, ESR, Mantoux, normal chest x-ray. Imaging by abdominal and pelvic ultrasonography or abdominal and pelvic CT scan is often very nonspecific. Findings on imaging have been suggested to be helpful but final diagnosis is revealed by culture and histology.

Diagnostic laparoscopy may aid in early diagnosis and safe management of genital tuberculosis, preventing unnecessary laparotomies. The accuracy of this modality in diagnosing genital tuberculosis is not proven though.

The various test so far used in diagnosing genital tuberculosis are varied. Although, apart from mycobacterium TB in culture, none of them are $100 \%$. Newer tests for the diagnosis of genital TB includes TB PCR, Bactec culture, Gene-xpert, QuantiFERON TB gold, QuantiFERON TB gold plus etc.

Bactec culture is a rapid radiometric culture and is based on measurement of carbon dioxide released by bacteria during growth in liquid medium. Radioactive carbon labelled substrate like palmitic acid or formic acid is used as marker for bacterial growth. It has higher sensitivity $80-90 \%$ and higher detection rate $7-10 \%$ and gives quicker result (5-10 days) and is also useful for drug susceptibility. The only disadvantage of this test is its cost. In this test homogenized sample is cultured using Bactec MGIT 960 system. 500 microlit. of sample is inoculated in MGIT tube containing $0.8 \mathrm{ml}$ PANTA antibiotics and growth supplements. MGIT tubes are incubated in Bactec 960 instruments. This system automatically identifies positive sample. ${ }^{3}$

Gene-xpert is a cartridge based nucleic acid amplification test (CBNAAT) for simultaneous rapid tuberculosis diagnosis and rapid antibiotic sensitivity test and require less than 2 hours for result. It is an automated diagnostic test that can identify MTB-DNA and resistance to Rifampicin. It has specificity of $99 \%$. In this test $1 \mathrm{ml}$ of homogenized sample is added to $2 \mathrm{ml}$ of Gene-xpert sample reagent. Mixture is vortexed for 30 seconds. The sample is left to stand for 15 minutes at room temperature and then $2 \mathrm{ml}$ of mixture sample is transferred to the test cartridge. Cartridge is loaded onto the xpert instrument. Results will be reported as positive or negative and sensitivity by RIF resistance determining region of the rpoB gene with molecular beacons within 2 hours. ${ }^{4}$

The objective of this study was to compare Bactec, Genexpert and HPE in the diagnosis of genital tuberculosis in infertility patients.

\section{METHODS}

This study was conducted in department of obstetrics and gynecology, in collaboration with department of pathology and department of microbiology in S.V.B.P. Hospital L.L.R.M. Medical College Meerut from June 2018 to May 2019.
This was a prospective case control study including 100 patients who underwent diagnostic laparoscopy for infertility. Clearance was obtained from Ethical committee of hospital before starting the study. In this study total of 100 patients were enrolled who presented with Primary or Secondary infertility. After fulfilling inclusion and exclusion criteria, they were recruited to undergo Diagnostic Laparoscopy and hysteroscopy. Each patient was explained regarding the procedure and proper written consent was taken after thorough history, examination and investigations. Endometrial samples were collected from every patients and were subjected to further testing.

\section{Inclusion criteria}

- Women with primary or secondary infertility suspected for genital tuberculosis

- Infertile women with normal husband semen analysis.

\section{Exclusion criteria}

- Women with HIV positive status

- Fibroid distorting the endometrial cavity

- Congenital abnormalities of uterus

- Cervical polyp and malignancy.

All suspected cases of genital Tuberculosis presenting with primary and secondary infertility were included in this study. Known cases of malignancy and pregnancy excluded from study. Detailed history, general physical and gynaecological examination followed by baseline investigations. All patients underwent diagnostic laparoscopy under general anaesthesia preferable in premenstrual phase (D21-D28) and were evaluated for suggestive findings of genital tuberculosis and endometrial biopsy taken. Samples were divided in three parts. First two samples kept in normal saline send for Bactec culture and Gene-xpert. Third sample in 10\% formalin for histopathology. Patients profile, history, investigations, laparoscopic findings, tests ordered and finally their result were recorded in proforma and analyzed.

\section{Statistical analysis}

Descriptive statistics was used to explain the data using Microsoft excel and MedCalc software.

\section{RESULTS}

\section{Demographic profile of patients}

\section{Age of the patients}

In this study, the youngest patients were of 23 years and eldest was of 34 years of age. The mean age of the patients was 27.94. Majority of the patients in this study was between $26-30$ years (51\%). 


\section{Type of infertility}

Out of 100 patients, $69(69 \%)$ patients had primary infertility and $31(31 \%)$ patients had secondary infertility (Table 1).

Table 1: Distribution of type of infertility.

\begin{tabular}{|ll|l|}
\hline Type of infertility & No. of patients & Percentage \\
\hline Primary & 69 & $69 \%$ \\
\hline Secondary & 31 & $31 \%$ \\
\hline Total & 100 & $100 \%$ \\
\hline
\end{tabular}

Table 2: Maximum and minimum duration of infertility.

\begin{tabular}{|lll|l|l|}
\hline Minimum & Maximum & Range & Mean & SD \\
\hline 3 years & 15 years & 12 years & 6.35 & 2.1648 \\
\hline
\end{tabular}

Table 3: Distribution of duration of infertility.

\begin{tabular}{|lll|}
\hline Duration of infertility & No. of patients & Percentage \\
\hline $1-5$ years & 34 & $34 \%$ \\
\hline $6-10$ years & 60 & $60 \%$ \\
\hline$>10$ years & 6 & $6 \%$ \\
\hline Total & 100 & $100 \%$ \\
\hline
\end{tabular}

\section{Duration of infertility}

The overall mean duration of infertility among the patients ranges from minimum 3 years to maximum 15 years. However more than half of the patients had infertility of 6-10 years. The overall mean duration of infertility was 6.35 years (Table 2 and 3 ).

Table 4: Distribution according to history of TB in patients or in family.

\begin{tabular}{|ll|l|}
\hline & Percentage & Absent \\
\hline Family history of TB & 11 & 89 \\
\hline Past history of TB & 19 & 81 \\
\hline
\end{tabular}

Table 5: Distribution of patients according to laparoscopic findings.

\begin{tabular}{|lll|}
\hline Laparoscopic findings & Frequency & Percentage \\
\hline Normal & 61 & $61 \%$ \\
\hline Findings s/o FGTB & 39 & $39 \%$ \\
\hline Total & 100 & $100 \%$ \\
\hline
\end{tabular}

Obstetric history

- Parity and abortions

Out of total 100 patients 69 patients were nulliparous and 5 patients were paral and 26 patients had history of abortion. Out of 26 patients with abortion 22 had history of one abortion and 4 patients had history of two abortions.

\section{Different menstrual patterns}

Majority of women had normal menstrual function i.e., 71 , oligomenorrhoea in 16 patients, hypomenorrhea in 6 patients, 6 patients had menorrhagia and 1 patient had secondary amenorrhoea.

History of tuberculosis in patients or in family

Out of total 100 patients 11 had family history of tuberculosis and 19 had past history of tuberculosis (Table 4).

\section{Distribution on the basis of ESR}

Out of total 100 patients 16 patients had raised ESR and 84 patients had normal ESR.

\section{Distribution of patients according to Mantoux}

Induration more than $10 \mathrm{~mm}$ indicate Positive reaction between 48-72 hours. Out of total 100 patients, 21 patients had positive result and 79 had negative result.

Out of 21 Mantoux positive patients, 15 had positive findings s/o genital tuberculosis on laparoscopy and 6 had normal laparoscopic findings.

Distribution of patients according to laparoscopic findings

Although laparoscopy is an invasive procedure, but it is an important tool in the evaluation of infertility and in the diagnosis of various pelvic conditions. With the help of laparoscope ovaries, fallopian tubes, peritoneal cavity, uterine surface etc inspected for stigmata of genital tuberculosis, that aids in the diagnosis of genital tuberculosis. The laparoscopic findings suggestive of genital tuberculosis may vary from normal appearance to tubercles on the surface, fimbrial block, fimbrial phimosis, tubal beading, peritubal adhesions, periovarian adhesions, tub ovarian mass, hydrosalpinx and rigid tubes etc.

In the present study, laparoscopic findings suggested that $61 \%$ patients of the study patients had normal findings and $39 \%$ patients had laparoscopic features suggestive of genital tuberculosis (Table 5 and 6).

\section{Peritoneum}

On laparoscopy $67 \%$ patients had normal peritoneal findings. While tubercle, peritoneal inclusion cysts and adhesions were found in $6 \%, 8 \%$ and $19 \%$ respectively. 
Table 6: Distribution of patients according to various laparoscopic findings.

\begin{tabular}{|c|c|c|c|}
\hline Laparoscopy & Findings & Frequency & Percentage \\
\hline \multirow{5}{*}{ Peritoneum } & Normal & 67 & $67 \%$ \\
\hline & Tubercles & 6 & $6 \%$ \\
\hline & Adhesions & 19 & $19 \%$ \\
\hline & Peritoneal inclusion cyst & 8 & $8 \%$ \\
\hline & Total & 100 & $100 \%$ \\
\hline \multirow{4}{*}{ Uterus } & Normal in shape and contour & 90 & $90 \%$ \\
\hline & Tubercles & 4 & $4 \%$ \\
\hline & Increased vascularity & 6 & $6 \%$ \\
\hline & Total & 100 & $100 \%$ \\
\hline \multirow{6}{*}{ Ovaries } & Normal & 62 & $62 \%$ \\
\hline & Bulky/PCOD & 11 & $11 \%$ \\
\hline & Functional Ovarian cyst & 16 & $16 \%$ \\
\hline & Peri ovarian adhesions & 6 & $6 \%$ \\
\hline & Endometriotic cyst & 5 & $5 \%$ \\
\hline & Total & 100 & $100 \%$ \\
\hline \multirow{10}{*}{ Fallopian tube } & Normal in appearance & 63 & $63 \%$ \\
\hline & Unilateral hydrosalpinx & 3 & $3 \%$ \\
\hline & Bilateral hydrosalpinx & 4 & $4 \%$ \\
\hline & Tubercles & 4 & $4 \%$ \\
\hline & Peritubal adhesions & 15 & $15 \%$ \\
\hline & Bilateral tubo-ovarian mass & 6 & $6 \%$ \\
\hline & Beaded appearance & 5 & $5 \%$ \\
\hline & Total & 100 & $100 \%$ \\
\hline & Perihepatic adhesions & 2 & $2 \%$ \\
\hline & Bowel and omental adhesions & 3 & $3 \%$ \\
\hline \multirow{5}{*}{ Chromopertubation } & Bilateral spill of dye & 66 & $66 \%$ \\
\hline & Unilateral spill of dye & 9 & $9 \%$ \\
\hline & Absent spill of dye & 19 & $19 \%$ \\
\hline & Loculated spill of dye & 6 & $6 \%$ \\
\hline & Total & 100 & $100 \%$ \\
\hline
\end{tabular}

\section{Uterus}

Out of total, $90 \%$ patients had normal uterine findings while $4 \%$ patients had tubercles and $6 \%$ had increased vascularity.

\section{Ovaries}

A total $62 \%$ patients had normal looking ovaries while $5 \%, 6 \%, 11 \%$ and $16 \%$ patients had endometrial cysts, peri-ovarian adhesions, bulky ovaries and functional ovarian cysts respectively.

\section{Fallopian tube}

A total $63 \%$ patients had normal appearing fallopian tubes while $3 \%, 4 \%, 4 \%, 5 \%, 6 \%$ and $15 \%$ patients had unilateral hyrosalpinx, bilateral hydrosalpinx, tubercles, beaded tubes, T-O mass and peritubal adhesions respectively.
A total $2 \%$ patients had perihepatic adhesions and $3 \%$ patients had bowel and omental adhesions.

Table 7: Distribution of patients according to hysteroscopic findings.

\begin{tabular}{|lll|}
\hline Hysteroscopic findings & Frequency & Percentage \\
\hline Normal & 88 & $88 \%$ \\
\hline Findings s/o FGTB & 12 & $12 \%$ \\
\hline Total & 100 & $100 \%$ \\
\hline
\end{tabular}

\section{Chromopertubation}

On chromopertubation $66 \%$ patients had bilateral spill of dye, $6 \%$ patients had loculated spill of dye, $9 \%$ had unilateral spill of dye and $19 \%$ patients had absent spill of dye.

Distribution of patients according to hysteroscopic findings 
On hysteroscopy out of total 100 patients 88 patients had normal study, 4 patients had bald endometrium, 5 patients had distorted ostium and 3 patients had synechiae (Table 7 and 8).

Distribution of samples according to Bactec culture

Out of 100 samples Bactec was positive in 2 samples $(2 \%)$, both had also findings s/o genital tuberculosis on laparoscopy (Table 9 and 10).
Table 8: Distribution of patients according to various hysteroscopic findings suggesting FGTB.

\begin{tabular}{|l|l|l|}
\hline Findings & Frequency & Percentage \\
\hline Bald endometrium & 4 & $4 \%$ \\
\hline Distorted ostium & 5 & $5 \%$ \\
\hline Synechiae & 3 & $3 \%$ \\
\hline Normal & 88 & $88 \%$ \\
\hline Total & 100 & $100 \%$ \\
\hline
\end{tabular}

Table 9: Distribution of samples according to Bactec culture.

\begin{tabular}{|l|l|lll|}
\hline & $\begin{array}{l}\text { Total } \\
\text { samples }\end{array}$ & $\begin{array}{l}\text { No. of positive sample for } \\
\text { Bactec }\end{array}$ & $\begin{array}{l}\text { No. of negative } \\
\text { sample }\end{array}$ & Percentage \\
\hline Laparoscopic finding s/o FGTB & 39 & 2 & 37 & $5.1 \%$ \\
\hline Normal laparoscopic findings & 61 & 0 & 61 & $0 \%$ \\
\hline Total & 100 & 2 & 98 & \\
\hline
\end{tabular}

Table 10: Distribution according to Bactec culture.

\begin{tabular}{|c|c|c|c|c|c|}
\hline & Sensitivity & Specificity & PPV & NPV & p value \\
\hline Bactec & 5.12 & 100 & 100 & 62.24 & 0.0739 \\
\hline
\end{tabular}

Table 11: Distribution of samples according to Gene-xpert.

\begin{tabular}{|c|c|c|c|c|}
\hline & $\begin{array}{l}\text { Total } \\
\text { samples }\end{array}$ & $\begin{array}{l}\text { No. of positive } \\
\text { samples }\end{array}$ & $\begin{array}{l}\text { No. of negative } \\
\text { samples }\end{array}$ & $\begin{array}{l}\text { Positive samples } \\
\text { percentage }\end{array}$ \\
\hline Laparoscopic findings s/o FGTB & 39 & 2 & 37 & $5.10 \%$ \\
\hline Normal laparoscopic findings & 61 & 1 & 60 & $1.63 \%$ \\
\hline
\end{tabular}

Table 12: Distribution of samples according to Gene-xpert.

\begin{tabular}{|ll|l|ll|l|}
\hline & Sensitivity & Specificity & PPV & NPV & p value \\
\hline Gene-xpert & 5.128 & 98.36 & 66.66 & 61.85 & 0.318 \\
\hline
\end{tabular}

Table 13: Distribution of samples according to HPE.

\begin{tabular}{|c|c|c|c|c|}
\hline & Total & $\begin{array}{l}\text { No. of positive } \\
\text { samples }\end{array}$ & $\begin{array}{l}\text { No. of negative } \\
\text { samples }\end{array}$ & $\begin{array}{l}\text { Positive sample } \\
\text { percentage }\end{array}$ \\
\hline Laparoscopic findings s/o FGTB & 39 & 1 & 38 & $2.56 \%$ \\
\hline Normal on laparoscopy & 61 & 0 & 61 & $00 \%$ \\
\hline
\end{tabular}

\section{Distribution of samples according to Gene-xpert}

Out of total 100 samples Gene-xpert was positive in 3 samples. Out of 3, 2 had findings s/o genital tuberculosis and 1 had normal finding on laparoscopy and none of them were Rifampicin resistant (Table 11 and 12).

Distribution of samples according to HPE (histopathology)

On histopathological examination of endometrium, 1 case was positive for tubercular endometritis, non-specific endometritis in 1 case, proliferative endometrium (anovulatory) was found in 40 cases and secretory endometrium was found in 58 cases (Table 13, 14 and $15)$.

Table 14: Distribution of different histopathological pattern of samples.

\begin{tabular}{|lll|}
\hline Histopathology & Frequency & Percentage \\
\hline Tubercular endometritis & 1 & $1 \%$ \\
\hline Non-specific endometritis & 1 & $1 \%$ \\
\hline Proliferative phase & 40 & $40 \%$ \\
\hline Secretory phase & 58 & $58 \%$ \\
\hline Total & 100 & $100 \%$ \\
\hline
\end{tabular}


Table 15: Distribution of HPE samples.

\begin{tabular}{|c|c|c|c|c|c|}
\hline & Sensitivity & Specificity & PPV & NPV & p value \\
\hline HPE & 2.56 & 100 & 100 & 61.61 & 0.20 \\
\hline
\end{tabular}

Table 16: Comparison of diagnostic yield of various tests.

\begin{tabular}{|llllll|}
\hline Tests & Sensitivity & Specificity & PPV & NPP & p value \\
\hline Bactec & $5.12 \%$ & $100 \%$ & $100 \%$ & $62.24 \%$ & 0.0739 \\
\hline Gene-xpert & $5.12 \%$ & $98.36 \%$ & $66.66 \%$ & $61.85 \%$ & 0.318 \\
\hline HPE & $2.56 \%$ & $100 \%$ & $100 \%$ & $61.61 \%$ & 0.20 \\
\hline
\end{tabular}

\section{DISCUSSION}

FGTB has become a challenging disease both from diagnostic and therapeutic point of view as it has very few characteristic symptoms. On the basis of clinical presentations, a woman cannot be diagnosed with FGTB.

The diagnostic dilemma arises because of the varied clinical presentation of the disease confounded by diverse results on imaging, laparoscopy, histopathology and mixed bag of bacteriological and serological tests, each of which has its limitation in diagnostic sensitivity and specificity (Table 16).

Table 17: Comparison of type of infertility in various studies.

\begin{tabular}{|l|lll|}
\hline Author & Year & $\begin{array}{l}\text { Primary } \\
\text { infertility }\end{array}$ & $\begin{array}{l}\text { Secondary } \\
\text { infertility }\end{array}$ \\
\hline Kiran et al & 2017 & $72 \%$ & $28 \%$ \\
\hline Jindal N et al & 2017 & $76 \%$ & $24 \%$ \\
\hline Mahesweta et al & 2017 & $74.3 \%$ & $25.7 \%$ \\
\hline Danish et al & 2018 & $60.6 \%$ & $39.4 \%$ \\
\hline Roopakshi et al & 2018 & $46.9 \%$ & $53.1 \%$ \\
\hline Chesta et al & 2018 & $74 \%$ & $26 \%$ \\
\hline Nikita et al & 2019 & $67 \%$ & $33 \%$ \\
\hline Present study & 2019 & $69 \%$ & $31 \%$ \\
\hline
\end{tabular}

Table 18: Comparison of history of tuberculosis.

\begin{tabular}{|c|c|c|}
\hline Author & Year & $\mathrm{H} / \mathrm{o}$ of $\mathrm{TB}$ \\
\hline Nidhi et al & 2017 & $6.29 \%$ \\
\hline $\begin{array}{l}\text { Roopakshi et } \\
\text { al }\end{array}$ & 2018 & $\begin{array}{l}11.2 \% \text { (family h/o TB) } \\
23.5 \% \text { (past h/o TB) }\end{array}$ \\
\hline Nikita et al & 2019 & $14.28 \%$ \\
\hline Present study & 2019 & $\begin{array}{l}\text { 11\% (family h/o TB) } \\
19 \% \text { (past } \mathrm{h} / \mathrm{o} \mathrm{TB})\end{array}$ \\
\hline
\end{tabular}

If patients are adequately treated before their tubes are irreversibly damaged, the chances of successful pregnancy are reasonably good therefore early diagnosis of genital tuberculosis is needed for better outcome.

Hystero-laparoscopy are useful to diagnose the FGTB by presence of adhesions, presence of tubercles etc., that can help to sort the highly suspicious FGTB patients.
Table 19: Comparison of percentage of laparoscopic findings.

\begin{tabular}{|ll|l|l|}
\hline Author & Year & $\begin{array}{l}\text { Normal } \\
\text { findings }\end{array}$ & $\begin{array}{l}\text { Abnormal } \\
\text { findings (s/o } \\
\text { GTB) }\end{array}$ \\
\hline Mala YM et al & 2017 & $73.3 \%$ & $26.6 \%$ \\
\hline Thangappah et a & 2018 & $53.8 \%$ & $46.2 \%$ \\
\hline Nikita et al & 2019 & $72 \%$ & $28 \%$ \\
\hline Diksha et al & 2019 & $60.3 \%$ & $39.7 \%$ \\
\hline Present study & 2019 & $61 \%$ & $39 \%$ \\
\hline
\end{tabular}

Table 20: Comparison of BACTEC positivity in various studies.

\begin{tabular}{|l|l|l|}
\hline Author & Year & Bactec positive (\%) \\
\hline Geetika et al & 2013 & $8.8 \%$ \\
\hline Riden et al & 2017 & $27 \%$ \\
\hline Mahesweta et al & 2017 & $2.85 \%$ \\
\hline Present study & 2019 & $2 \%$ \\
\hline
\end{tabular}

Table 21: Comparison of Gene-xpert positivity in different studies.

\begin{tabular}{|lll|}
\hline Author & Year & Gene-xpert positive (\%) \\
\hline Riden et al & 2017 & $1.6 \%$ \\
\hline Roopakshi et al & 2018 & $0 \%$ \\
\hline Danish et al & 2019 & $7.25 \%$ \\
\hline Diksha et al & 2019 & $5 \%$ \\
\hline Present study & 2019 & $3 \%$ \\
\hline
\end{tabular}

A total 100 infertile patients suspected of genital tuberculosis were included in this study out of which majority of patients $(69 \%)$ had primary infertility and $31 \%$ patients had secondary infertility (Table 17). Most of the women were in age group of 26-30 years (51\%) and mean age of the patients was 27.94 years with mean duration of infertility 6.35 years. Out of total 100 patients 11 had family h/o tuberculosis and 19 patients had h/o pulmonary tuberculosis in past (Table 18). A study done by Nikita et al in which $14.28 \%$ patients had history of tuberculosis. ${ }^{5}$

In this study majority of patients had normal menstrual pattern (71\%) while oligomenorrhoea in $16 \%$, hypomenorrhea in $6 \%$, menorrhagia in $6 \%$ and secondary 
amenorrhea in $1 \%$ patients. Comparable study done by Mahesweta et al in $2017 .^{6}$

Table 22: Comparison of percentage of endometrial tuberculosis on HPE.

\begin{tabular}{|lll|}
\hline Author & Year & HPE S/O FGTB (\%) \\
\hline Geetika et al & 2013 & $2.6 \%$ \\
\hline Srivastava et al & 2014 & $1.3 \%$ \\
\hline Mahesweta et al & 2017 & $0 \%$ \\
\hline Roopakshi et al & 2018 & $1.23 \%$ \\
\hline Thangappah & 2018 & $4 \%$ \\
\hline Nikita et al & 2019 & $7.14 \%$ \\
\hline Danish et al & 2019 & $0 \%$ \\
\hline Present study & 2019 & $1 \%$ \\
\hline
\end{tabular}

Out of 100 patients 16 patients had raised ESR and 84 patients had normal ESR and out of 100 patients 21 patients had positive result $(>10 \mathrm{~mm})$ and 79 had negative Mantoux test.

In the present study, laparoscopic findings suggested that $61 \%$ patients of the study patients had normal findings and $39 \%$ patients had laparoscopic features suggestive of genital tuberculosis. Various laparoscopic findings shown in Table 6.

Comparable study done by Diksha et al in which $60.3 \%$ patients had normal laparoscopic findings and 39.7\% patients had laparoscopic findings suggestive of genital tuberculosis like delayed dye spillage $6 \quad(8.8 \%)$, hydrosalpinx present $7(10.3 \%)$, beaded appearance of fallopian tubes $5(7.3 \%)$, granulomas $1(1.4 \%)$, pelvic congestion $1(1.4 \%)$, pelvic adhesions $5(7.3 \%)$ and bilateral dye spillage absent $15(22 \%)$ and unilateral dye spillage seen $10(14.7 \%)^{7}$

This study results are comparable with various studies done in past (Table 19).

\section{Hysteroscopy}

On hysteroscopic visualization of the uterine cavity in genital TB may show normal cavity with bi lateral open ostia in early stage.

In this study on hysteroscopy out of Total 100 patients 88 patients $(88 \%)$ had normal study,4 patients had bald endometrium, 5 patients had distorted ostium and 3 patients had synechiae.

Comparable study done by Mahesweta et al in which on hysteroscopy, 29 cases $(82.9 \%)$ of the patients had normal findings and 3 cases had hysteroscopic features suggestive of GTB. ${ }^{8}$ Bald endometrium, distorted ostium, synechiae was present in $12.5 \%, 12.5 \%, 12.5 \%$ cases respectively. In the study conducted by Ashabaxi et al, the intrauterine synechie was observed only in $3.57 \%$ and fibrosed ostia in $7.14 \%$.

\section{Bactec culture}

It is a type of liquid culture and automatically identifies positive samples. In this study out of 100 samples Bactec was positive in 2 samples (2\%). Both Bactec positive sample also had laparoscopic findings suggestive of FGTB. On the basis of this sensitivity, specificity, positive predictive value and negative predictive value was $5.26 \%, 100 \%, 100 \%$ and $62.24 \%$ respectively. Comparable study done by Mahesweta et al, in which TB Bactec was positive in $2.85 \%(n=1)$, and none of the cases had histopathological evidence of genital TB.

Various studies of percentage of Bactec positivity are compared which were done in past with this study (Table 20).

\section{Gene-xpert}

Gene-xpert is a cartridge based nucleic acid amplification test (CBNAAT) for simultaneous rapid tuberculosis diagnosis and rapid antibiotic sensitivity test, (Less than 2 hours). It is an automated diagnostic test that can be identify MTB-DNA and resistance to Rifampicin. WHO endorsed the Gene-xpert for MTB diagnosis in endemic countries in December 2010. It has specificity of $99 \%$. In this study out of total 100 samples Gene-xpert was positive in 3 samples (3\%). Out of 3 positive result containing patients 2 had laparoscopic findings suggestive of FGTB and 1 had normal laparoscopic findings. On the basis of this sensitivity, specificity, positive predictive value and negative predictive value was $5.26 \%, 98.36 \%, 66.66 \%$ and $61.85 \%$ respectively. Comparable study done by Riden et al in which Genexpert positive in $1.6 \%$ patients. ${ }^{9}$ Various studies of Genexpert positivity are compared (Table 21 ).

\section{HPE (histopathological evaluation)}

Demonstration of granuloma with or without Langerhans giant cell on histopathology is diagnostic of genital TB. In this study on histopathological examination of endometrium, 1 case $(1 \%)$ was positive for tubercular endometritis, non-specific endometritis in 1 case $(1 \%)$, proliferative endometrium (anovulatory) was found in 40 cases $(40 \%)$ and secretory endometrium was found in 58 cases $(58 \%)$.

One positive result having tubercular endometritis also had laparoscopic finding suggestive of FGTB as well as positive for Bactec and Gene-xpert. On the basis of this sensitivity, specificity, positive predictive value and negative predictive value was $2.56 \%, 100 \%, 100 \%$ and $61.61 \%$ respectively. Comparable study done by Roopakshi et al, in which on histopathological examination of endometrium, 1 case $(1.23 \%)$ was found positive for tubercular endometritis, proliferative endometrium (anovulatory) was found in 34 cases $(41.9 \%)$, non-specific endometritis in 1 case $(1.23 \%)$ and secretory endometrium was found in 45 cases $(55.55 \%)$. 
Various studies are compared on the basis of percentage of endometrial tuberculosis on HPE Table. ${ }^{22}$

\section{CONCLUSION}

Female genital tuberculosis (FGTB) has become a challenging disease from diagnostic point of view despite of availability of potent drugs for treatment as it has very few characteristic symptoms. The diagnosis of genital tuberculosis is seldom suggested from history or physical examinations. The diagnostic dilemma arises because of the varied presentation of the disease confounded by diverse results on imaging, laparoscopy, histopathology and mixed bag of bacteriological and serological tests, each of which has its limitation in diagnostic sensitivity and specificity. If the patients are adequately treated before their tubes are irreversibly damaged, the chances of successful pregnancy are reasonably good. Although laparoscopy is an invasive procedure, it aids in visual inspection of ovaries, fallopian tubes, peritoneal cavity and biopsy of the tubercular lesions. The laparoscopic findings of genital TB may vary from normal appearance to tubercle on surface, fimbrial block, tubal beading, peritubal adhesions, T-O mass, hydrosalpinx etc. It aids in speedy diagnosis and therefore, early implementation of treatment and thereby preventing massive and sometimes irreparable damage to vital reproductive structures. Therefore, diagnostic laparoscopy is recommended in all clinically suspicious cases of genital TB.

Combination of HPE and microbiological tests like Bactec, Gene-xpert are important method for detection of genital TB. Although Bactec and Gene-xpert is said to have high sensitivity and high specificity but still there is limited role in the early diagnosis of genital TB from endometrial sample because of regular shedding of endometrial lining during each menstrual cycle.

Endometrial biopsy on Histopathology shows not only Tubercular endometritis but also gives hormone response on endometrium, local factors of endometrium concerning non-specific and specific infections and anovulatory cycles.

Diagnostic dilemma of genital tuberculosis still exist, therefore more larger case control studies are needed to find out more sensitive and specific tests to diagnose genital TB i.e. despite of availability of various techniques, diagnostic dilemma for genital TB still exist. Until date, none of the available tests can pick up all cases of genital tuberculosis.

Funding: No funding sources Conflict of interest: None declared
Ethical approval: The study was approved by the Institutional Ethics Committee

\section{REFERENCES}

1. Gatongi DK, Gital G, Kay V, Ngwenya S, Lafong C, Hasan A. Female genital tuberculosis. Obstet Gynaecol. 2005;54:927-31.

2. Bhanu NV, Singh UB, Chakraborty M, Suresh N, Arora J, Rana $\mathrm{T}$, Takkar $\mathrm{D}$, et al. Improved diagnostic value of PCR in diagnosis of female genital tuberculosis leading to infertility. $\mathrm{J}$ Med Microbiol. 2005;54:927-31.

3. Becton Dickinson. Baclec MGIT SIRE drug kit package insert - Beckton Dicldnson, Sparks, MD., 2010. Available at: http:// www.bd.com /ds/technical Cemer/inserts/PPI 18JAA<201006).pdf.

4. Ateah AI. Souad M, Maha M, Dowaidi AI, Noura A, Khizzi E. Evaluation of direct detection of mycobacterium tuberculosis complex in respiratory and non-respiratory clinical specimens using the Cepheid Gene Xpert R system. Saudi Med J. 2012;33(10):1100-5.

5. Figueroa-Damian R, Martinez-Velazco I, VillagranaZesati R. Tuberculosis of the female reproductive tract: effect on function. Int $\mathrm{J}$ Fertil Menopausal Stud. 1996;41(4):430-6.

6. Lakshmi V, Patil MA, Subhadha K, Himabindu V. Isolation of mycobacteria by BACTEC 460 system from clinical specimens. Ind $\mathrm{J}$ Med Micribiol. 2006;24(2):124-6.

7. Arpitha VJ. Diagnosis of genital tuberculosis: correlation between polymerase chain reaction positivity and laparoscopic findings. Int $\mathrm{J}$ Reprod Contracept Obstet Gyanecol. 2016;5(10):3425-32.

8. Fayez JA, Mutie G, Schneider PJ. The diagnostic value of hysterosalpingography and laparoscopy in infertility investigation. Int J Fertil. 1988;33(2):98101.

9. Thangappah RB, Paramasivan $\mathrm{CN}$, Narayan S. Evaluationg PCR, culture and HPE for diagnosis of female genital tuberculosis. Indian J Med Res. 2011;134(1):40.

Cite this article as: Chaudhary R, Dhama V, Singh $\mathrm{M}$, Singh S. Comparison of diagnostic accuracy of bactec culture, gene-xpert and histopathology in the diagnosis of genital tuberculosis in women with infertility. Int J Reprod Contracept Obstet Gynecol 2020;9:1614-21. 